\title{
Effect of Hedging-Integrated Rule Curves on the Performance of the Pong Reservoir (India) During Scenario-Neutral Climate Change Perturbations
}

\author{
A. J. Adeloye ${ }^{1}$ - B.-S. Soundharajan ${ }^{1}$ - C. S. P. Ojha ${ }^{2}$. \\ R. Remesan ${ }^{3}$
}

Received: 8 January 2015 / Accepted: 27 October 2015 /

Published online: 10 November 2015

(C) The Author(s) 2015. This article is published with open access at Springerlink.com

\begin{abstract}
This study has evaluated the effects of improved, hedging-integrated reservoir rule curves on the current and climate-change-perturbed future performances of the Pong reservoir, India. The Pong reservoir was formed by impounding the snow- and glacial-dominated Beas River in Himachal Pradesh. Simulated historic and climate-change runoff series by the HYSIM rainfall-runoff model formed the basis of the analysis. The climate perturbations used delta changes in temperature (from $0^{\circ}$ to $+2{ }^{\circ} \mathrm{C}$ ) and rainfall (from -10 to $+10 \%$ of annual rainfall). Reservoir simulations were then carried out, forced with the simulated runoff scenarios, guided by rule curves derived by a coupled sequent peak algorithm and genetic algorithms optimiser. Reservoir performance was summarised in terms of reliability, resilience, vulnerability and sustainability. The results show that the historic vulnerability reduced from $61 \%$ (no hedging) to $20 \%$ (with hedging), i.e., better than the $25 \%$ vulnerability often assumed tolerable for most water consumers. Climate change perturbations in the rainfall produced the expected outcomes for the runoff, with higher rainfall resulting in more runoff inflow and vice-versa. Reduced runoff caused the vulnerability to worsen to $66 \%$ without hedging; this was improved to $26 \%$ with hedging. The fact that improved operational practices involving hedging can effectively eliminate the impacts of water shortage caused by climate change is a significant outcome of this study.
\end{abstract}

Keywords Climate change $\cdot$ Genetic algorithms $\cdot$ Hedging $\cdot$ Reservoir operation $\cdot$ Reservoir performance evaluation $\cdot$ Rule curves

\section{A. J. Adeloye \\ A.J.Adeloye@hw.ac.uk}

1 Institute for Infrastructure and Environment, Heriot-Watt University, Edinburgh, UK

2 Department of Civil Engineering, IIT-Roorkee, Roorkee, India

3 Cranfield Water Science Institute, Cranfield University, Bedford, UK 


\section{Introduction}

Effective Reservoir operation is important to accommodate the inevitable differences between the hydrology used for reservoir planning and the prevailing hydrology when operating the reservoir. Climate change is predicted to affect the hydrology of most regions through its influence on temperature, rainfall, evapotranspiration, etc., which may further the divergence between the planning and operational hydrological situations (IPCC 2007).

Several studies have investigated the effects of climate change on reservoirs including Fowler et al. (2003), Nawaz and Adeloye (2006), Burn and Simonovic (1996), and Li et al. (2009); most of these have reported worsening reservoir performance as a consequence of climatic change. Relatively more recently, Raje and Mujumdar (2010) investigated the effect of hydrological uncertainty of climate change predictions on the performance of the Hirakud reservoir on the Mahanadi River in Orissa, India and found worsening reliability and vulnerability situations in the future. Most of these studies used outputs of large scale GCMs that were then downscaled to the catchment scale using either the statistical or dynamical (i.e., regional climate models) downscaling protocols. Fowler et al. (2007) discuss the pros and cons of these two approaches but despite their popularity for water resources climate change impact studies, there still remains a lot of uncertainties in both the broad-scale GCM predictions and their corresponding catchment scale downscaled hydro-climatology as noted by Raje and Mujumdar (2010). Vicuna et al. (2012) recommend the use of delta-perturbations as way of avoiding these uncertainties while Adeloye et al. (2013) discuss the nature of these uncertainties and the problems they pose for decision making. This study also adopted deltaperturbations approach to eliminate such uncertainties and because it can readily identify systems tipping points, e.g., when a reservoir fails catastrophically in meeting water demand.

The Pong reservoir on the Beas River, India (see Fig. 1) principally provides irrigation water although, prior to its diversion to irrigation, the water first passes through turbines for generating electricity (Jain et al. 2007). Consequently, the current study is focusing on the irrigation function of the reservoir. The reservoir inflow is highly influenced by both the Monsoon rainfall and the melting glacier and seasonal snow from the Himalayas; consequently, its ability to satisfactorily perform its functions is susceptible to possible climate-change disturbances in these climatic attributes. For example, official data of the Central Electricity Authority (CEA) show that the electricity generated per MW of installed generating capacity on the Beas has dropped by $18 \%$ between 1998-1999 and 2012-2013 (SANDRP 2013). There is also evidence of increasing water scarcity for irrigation and, for a system that is inextricably linked to the socio-economic well-being of its region (Jain et al. 2007), any significant deterioration in performance or ability to meet demands will have far reaching consequences.

The Pong reservoir, like most reservoirs, is operated using rule curves which guide the operator's decision on the quantity of water to release based on the total available water at the beginning of each month. A schematic illustration of basic rule curves is shown in Fig. 2a, in which the operator will attempt to meet the full monthly demand whenever the total amount of water available (i.e., the starting storage level plus the expected inflow during the month) is in the interval $\left[\mathrm{LRC}_{\mathrm{m}}, \mathrm{URC}_{\mathrm{m}}\right]$ for the month $\mathrm{m}$ under consideration, where $\mathrm{LRC}_{\mathrm{m}}$ and $\mathrm{URC}_{\mathrm{m}}$ are, respectively, the ordinates of the lower and upper rule curves for month $\mathrm{m}$. No water is supplied in a given month if the water available is below the $\mathrm{LRC}_{\mathrm{m}}$. A fundamental assumption here is that the anticipated inflow during the month is known at the start. However, while various schemes for forecasting the future inflow are possible, this is still largely an uncertain 


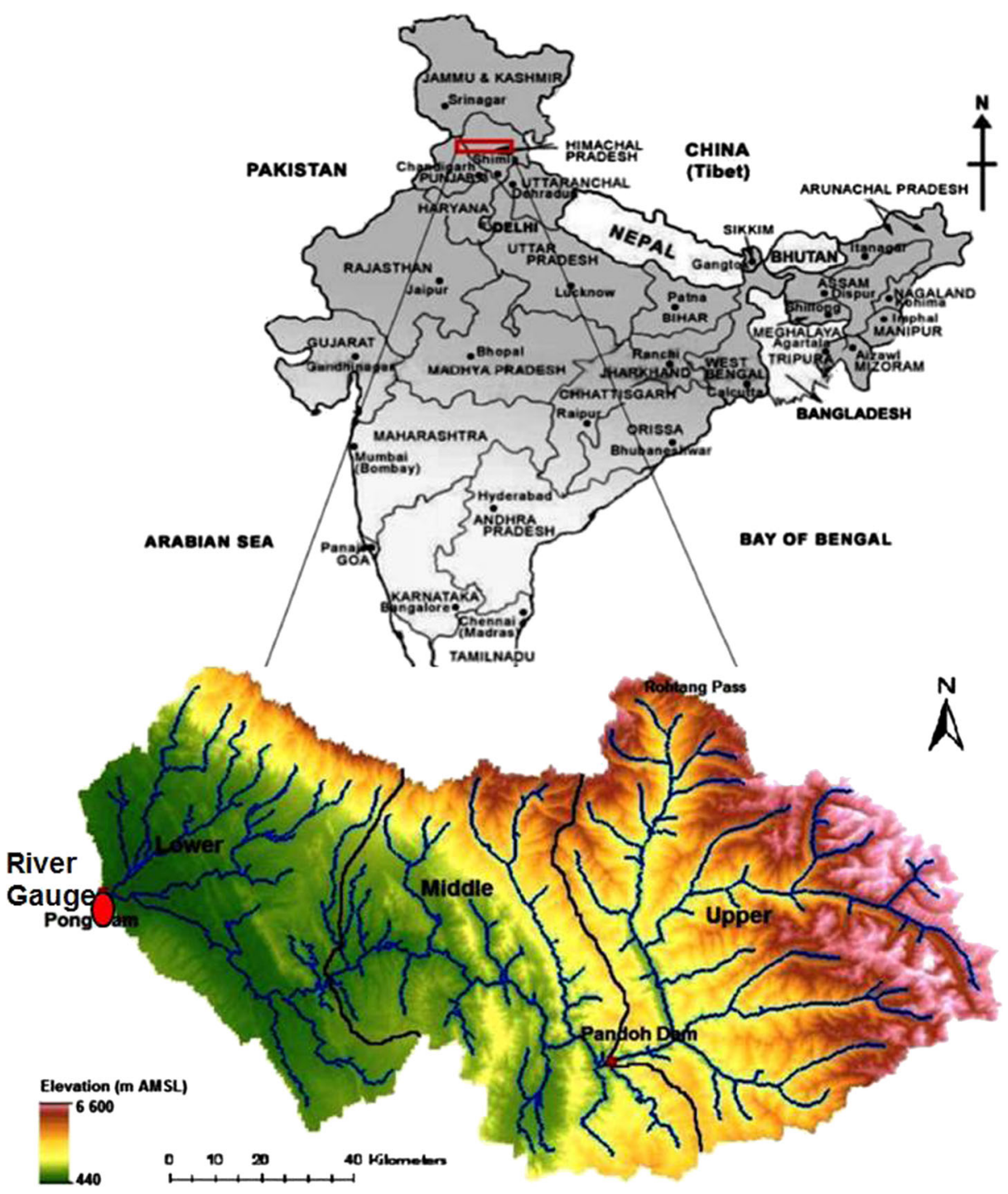

Fig. 1 Beas river basin

aspect of reservoir operation. Thus, as a way of eliminating the uncertainty, reservoir inflow will be assumed known at the start of each month, i.e., equal to the historic monthly flow.

However, much more problematic in the use of the basic rule curves illustrated in Fig. 2a for guiding reservoir operation is that it saves no water for impending droughts and the consequence is that the resulting shortage during such droughts can become very large. As the drought intensifies and less water comes into the reservoir, the inability to meet the target demand increases; the extreme situation is when the available water at the start of month $\mathrm{m}$ is at the $\mathrm{LRC}_{\mathrm{m}}$, implying that no water will be released from the reservoir for that month, potentially resulting in a maximum shortfall (or vulnerability). For example, Chiamsathit et al. (2014) reported vulnerabilities (or maximum single period shortages) of 67 and $88 \%$ 
Fig. 2 Schematic illustration of: a basic rule curves with no hedging; b standard operating policy (SOP); and $\mathbf{c}$ single stage hedgingintegrated rule curves

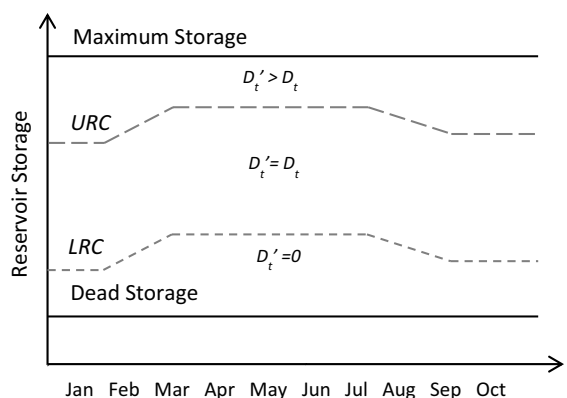

(a)

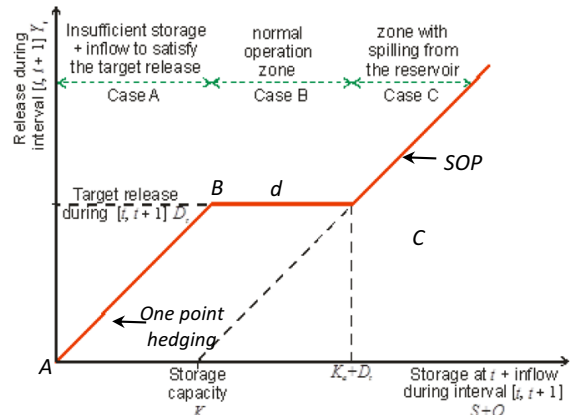

(b)

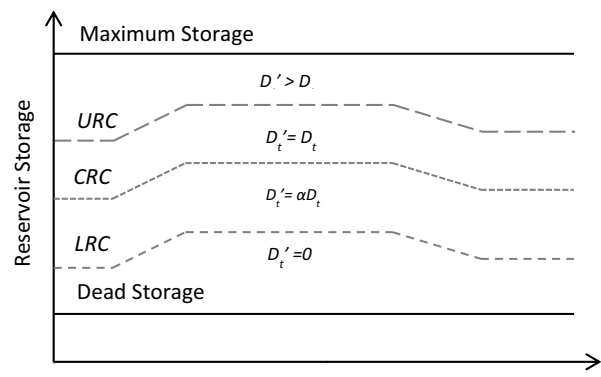

Jan Feb Mar Apr May Jun Jul Aug Sep Oct Nov

(c)

respectively for domestic and industrial water allocations at the Urbonratana reservoir in northeast Thailand when operated with basic rule curves such as those illustrated in Fig. 2a.

To avert situations of catastrophic vulnerability in reservoir operation, water rationing or hedging during normal operational periods is often carried out. The rationale for this is that it is better to have many small water shortages to which water users can readily adapt than a few large, crippling shortages (Tu et al. 2008; Eum et al. 2011). Fiering (1982) noted that water shortages below $25 \%$ of the target demand can generally be tolerated by users whereas anything above this threshold can be problematic.

For hedging to be effective, however, it must be well-timed and the supply reduction must be the right amount. Traditionally, hedging policy developments have employed the standard operating policy (SOP) and optimization to arrive at the optimal timing for release reductions 
as a result of which there now exist single point (see Fig. 2b) and multi-point hedging policies (Neelakantan and Pundarikanthan 1999; Hashimoto et al. 1982; Shih and ReVelle 1995; Draper and Lund 2004; Dariane and Karami 2014; You and Cai 2008; Tu et al. 2008; Shiau 2003; Peng et al. 2015). However, as seen in Fig. 2b, the single-point hedging policy is recommending supply cutback in the region of insufficient water availability, a situation that will only exacerbate the water shortage problem.

For hedging to be effective, it should be restricted to regions beyond point B in Fig. $2 \mathrm{~b}$ where there is sufficient water to meet the demand, i.e., it is a region of normal operation. Consequently, this study has radically departed from traditional approach by not using the SOP as the basis for the development of the optimised hedging policy; rather, the basic (or conventional) rule curves for the Pong formed the basis of the optimization for the development of the hedging. Because rule curves for the Pong were not made available by the operators of the reservoir, new ones were developed as part of this study using coupled sequent-peak and genetic algorithms (SPA-GA). To trigger hedging, a critical rule curve (CRC) that lies between the URC and LRC as illustrated in Fig. 2c was developed by a second stage GA optimisation. Taghian et al. (2014) attempted a similar approach to develop hedging policies for the Kosar and Chamshir reservoirs in Iran, which produced significant improvements in vulnerability performance of the reservoirs when compared to the use of conventional rule curves. They, however, had the benefit of existing rule curves for the reservoirs and did not investigate the effect of hedging within the context of climatic change or on other performance indices such as the resilience and sustainability.

Thus, the aim of this work is to develop optimised hedging policy for the Pong reservoir and assess the effectiveness of the policy in modulating the effects of water shortages for both the existing and climate change perturbed situations. The objectives are to:

- Calibrate, verify and validate a HYSIM rainfall-runoff model for the Pong catchment;

- Use the validated HYSIM model to simulate the historic runoff using the historic climate data;

- Derive optimized basic rule curves for the Pong using coupled SPA-GA approach

- Derive optimized hedging (trigger and rationing ratio) policy using GA for integration with the basic rule curves;

- Derive scenario-neutral future climate by applying reasonable delta perturbations to the rainfall and temperature; hence simulate climate-change induced runoff using HYSIM;

- Carry out reservoir behaviour simulations to assess the reliability, vulnerability, resilience and sustainability indices for the Pong with the simulated historic and climate change perturbed hydrology and make recommendations.

In the next section, further details about the methodology will be given. This is then followed by the presentation of the Case study. Next the results are presented and discussed and finally, the main conclusions are given.

\section{Methodology}

A flow chart of the adopted methodology is as illustrated in the schematic in Fig. 3; fuller descriptions are provided in the following sub-sections. 


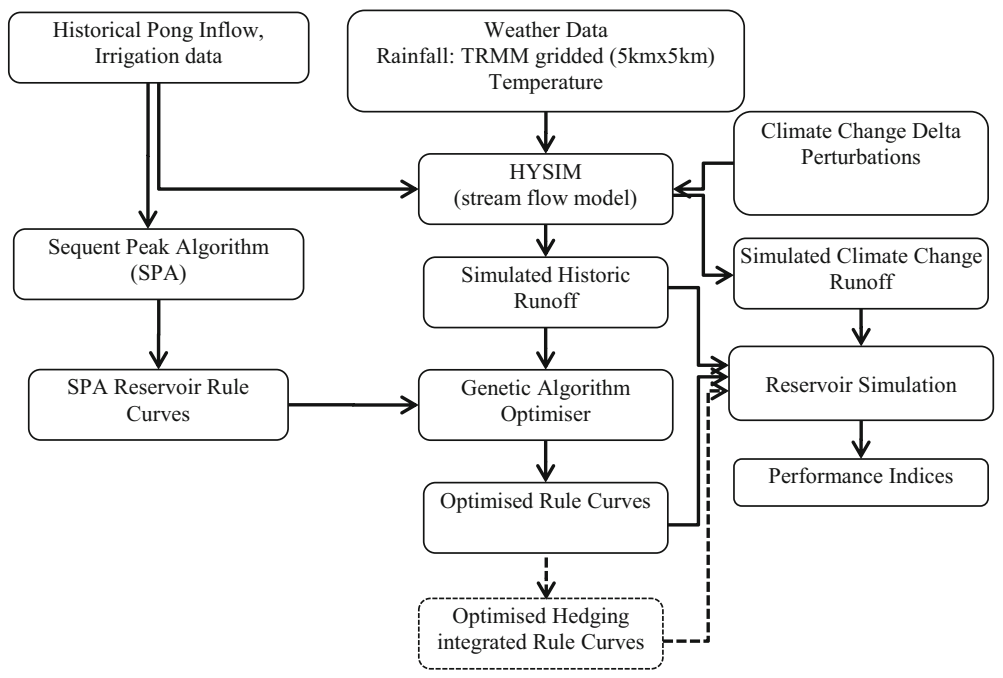

Fig. 3 Methodology flow chart

\subsection{Derivation of Basic Rule Curves}

The ordinates of the URC and LRC were derived in two stages:

i. initial estimates by the sequent peak algorithm (SPA); and

ii. a refined set of curves using the genetic algorithms optimisation.

\subsubsection{Sequent Peak Algorithm (SPA) Generation of Basic Curves}

The Sequent Peak Algorithm is a critical period technique for failure-free reservoir planning analysis and estimates the time series of the sequential deficit, $K_{t}$, and reservoir capacity, $K_{a}$ as follows (McMahon and Adeloye 2005):

$$
\begin{gathered}
K_{t+1}=\max \left(0, K_{t}+D_{t}-Q_{t}\right) ; t \in N \\
K_{a}=\max \left(K_{t+1}\right)
\end{gathered}
$$

where $K_{a}$ is the estimated reservoir capacity, $K_{t+1}$ and $K_{t}$ are respectively the sequential deficits at the end and start of time period $t, D_{t}$ is the demand during $t, Q_{t}$ is the inflow during $t$ and $N$ is the total number of time periods (herein months) in the data record. The analysis assumes that the reservoir is initially full, i.e., $K_{o}=0$. Where system failures and secondary processes such as evaporation loss must be accommodated, the modified form of the SPA (see Adeloye et al. 2001; Adeloye 2012) can be used. These secondary processes were neglected in the current analysis. The sequential deficits are thus the storage that must be maintained in the reservoir at the different dates to maintain the supply and hence provide the means for setting the initial ordinates of the rule curves. These initial estimates of the ordinates of the URC and LRC for each month of the year were obtained using: 


$$
\begin{aligned}
& U R C_{m}=\max \left(k_{y, m}\right), y=1, n ; m=1,12 \\
& L R C_{m}=\min \left(k_{y, m}\right), y=1, n ; m=1,12
\end{aligned}
$$

where $U R C_{m}$ and $L R C_{m}$ are, respectively, the upper and lower rule curves ordinates for month $m$, and $n(=N / 12)$ is the number of years in the data record. The two dimensional storage variable $k$ in Eqs. ( $3 \& 4$ ) is related to the one-dimensional storage variable $K$ in Eq. (1) by:

$$
k_{y, m}=K_{12(y-1)+m}
$$

i.e.,

$$
t=12(y-1)+m
$$

To refine the SPA-derived rule curves, they were optimised using GA.

\subsubsection{GA Optimisation of Rule Curves}

GA are a random search optimization scheme inspired by biological evolution and provides a robust method for searching for the optimum solution to complex problems. In a GA, the solution set is represented by a population of strings, which comprises a number of blocks each representing the individual decision variables of the problem. Strings are processed and combined according to their fitness (objective function value evaluated using the components in the string), in order to generate new strings that have the best features of two parent strings. Three fundamental operations are involved in manipulating strings and moving to a new generation: selection, crossover, and mutation. A detailed description of the GA is beyond the scope of this paper and interested readers are referred to the excellent text by Michalewicz (1992) for a comprehensive overview of the subject. Good examples of the application of GA optimisation to reservoir operation and rule curves studies include Reddy and Kumar (2006) and Wardlaw and Sharif (1999); Excellent reviews of the methodology are also provided by Hossain and El-shafie 2013 and Rani and Moreira (2010).

In this study, the objective (or fitness) function adopted for the GA optimisation to develop the basic rule curves was:

$$
\text { Minimise } \sum_{i=1}^{N}\left(D_{t}-D_{t}^{\prime}\right)^{2} ; \quad t \in N
$$

The constraints are as follows:

$$
\begin{gathered}
S_{t+1}=S_{t}+Q_{t}-D_{t}^{\prime}-E_{t}, \quad L R C_{m} \leq S_{t+1} \leq U R C_{m} \\
W A_{t}=S_{t}+Q_{t} \\
\text { if } W A_{t} \geq U R C_{m}, \quad D_{t}^{\prime}=S_{t}+Q_{t}-E_{t}-U R C_{m} \& E R_{t}=D_{t}^{\prime}-D_{t} \\
\text { if } U R C_{m} \geq W A_{t}>L R C_{m}, \quad D_{t}^{\prime}=D_{t} \& E R_{t}=0 \\
\text { if } W A_{t} \leq L R C_{m}, \quad D_{t}^{\prime}=0
\end{gathered}
$$


where $W A_{t}$ is the water available at beginning of time period (month) $t ; E R_{t}$ is excess release during time period $t, S_{t}$ is the storage at the beginning of $t, D_{t}^{\prime}$ is the actual release, $m$ is the month of the year and is related to the year $y$ and simulation period $t$ through Eq. (5b), $E_{t}$ is net evaporation (ignored), and all other symbols are as previously defined. The constraint on the right hand side of Eq. (7a) limits the available water in any given month to the interval $\left[L R C_{m}\right.$, $\left.U R C_{m}\right]$. The decision variables for the optimisation are the $U R C_{m}$ and $L R C_{m} ; m=1 . ., 12$ ordinates for each month $m$ of the year, giving a total of 24 variables, i.e., 12 values representing the 12 monthly ordinates for $U R C$ and a further 12 values representing the monthly ordinates for the $L R C$.

A real-value coding was used with the following parameters based on recommendations in the literature (e.g., Wardlaw and Sharif 1999) and the MATLAB documentation (MATLAB 2004): crossover fraction $=0.8$; mutation rate $=0.01$; number of elite children $=2$. The genetic operations were carried out over 500 generations; these were repeated 100 times to avoid any bias that can result from the initial random sampling to populate the strings. The best of the 100 repetitions was finally selected as the solution.

The SPA curves formed the basis for the initial sampling of the GA solution. For this, each ordinate of the curve was assumed to be uniformly distributed, with upper and lower limits defined by:

$$
\begin{gathered}
U R C=U\left[U R C_{m(S P A)}-\sigma_{U R C} ; U R C_{m(S P A)}+\sigma_{U R C}\right] ; y=1, n ; m=1,12 \\
L R C=U\left[L R C_{m(S P A)}-\sigma_{L R C} ; L R C_{m(S P A)}+\sigma_{L R C}\right] ; y=1, n ; m=1,12
\end{gathered}
$$

where U[.] is the uniform density function with upper and lower bounds as specified, $U R C_{m(S P A)}$ is the SPA upper rule curve ordinate in month $m, \sigma_{U R C}$ is the standard deviation calculated using all 12 SPA $U R C$ ordinates and $\sigma_{L R C}$ is the corresponding standard deviation for the $L R C$ ordinates. To avoid negative values for the uniform distribution limits, especially in the case of $L R C$, the limits in Eqs. (8) \& (9) were constrained to a minimum value of zero.

\subsection{Hedging Policy}

The optimised rule curves will still attempt to supply the full demand if the available water at the start of the month is anywhere in the interval $\left[\mathrm{LRC}_{\mathrm{m}}, \mathrm{URC}_{\mathrm{m}}\right]$, which will cause the reservoir level to fall much more rapidly towards the LRC. If this happens in a low inflow period, causing the water level to reach the LRC, the available water for release in subsequent months will be limited to just the inflow during the affected months (because there is no carryover water) and the resulting shortages may become very high, further exacerbating the systems vulnerability. A way to improve the situation is to hedge or save some of the water during normal operation, i.e., when the reservoir state is in the interval $\left[\mathrm{LRC}_{\mathrm{m}}, \mathrm{URC}_{\mathrm{m}}\right]$, and use the saved water to ameliorate some of the shortages during later dry periods.

The timing of the hedging and its amount are achieved in this study using a CRC that lies between the LRC and URC as shown schematically in Fig. 2c. The CRC thus represents the timing of hedging as follows:

$$
\text { if } U R C_{m} \geq W A_{t}>C R C_{m}, \quad D_{t}^{\prime}=D_{t} \& E R_{t}=0
$$




$$
\begin{gathered}
\text { if } C R C_{m} \geq W A_{t}>L R C_{m}, \quad D_{t}^{\prime}=\alpha D_{t} \& E R_{t}=0 \\
\quad \text { if } W A_{t} \leq L R C_{m}, \quad D_{t}^{\prime}=0 \\
1 \geq \alpha>0 ; \quad U R C_{m} \geq C R C_{m} \geq L R C_{m}
\end{gathered}
$$

where, $C R C_{m}$ is the critical rule curve ordinate for month $m(=1,2, \ldots, 12) ; \alpha$ is the rationing ratio and all other variables are as defined previously. The rationing ratio and the 12 ordinates of the CRC were determined by further GA optimisation using the same objective function used for optimising the main rule curves (see Eq. (6)) but with modified constraints given by Eq. 10 (a-d).

\subsection{Reservoir Behaviour Simulation and Performance Indices}

Reservoir simulation uses the mass balance equation shown in Eq. (7a). Four performance indicators of the reservoir, namely the reliability, resilience, vulnerability and sustainability indices were evaluated as follows (Hashimoto et al. 1982; McMahon et al. 2006; Adeloye 2012):

Reliability: this can be expressed either in the time-domain, $R_{t}$ (proportion of the total time period during which a reservoir can meet the target demand) or volume domain, $R_{v}$ (proportion of the total demand (volume) actually supplied) as follows:

$$
\begin{gathered}
R_{t}=N_{s} / N \\
R_{v}=\sum_{t=1}^{N} D_{t}^{\prime} / \sum_{t=1}^{N} D_{t}
\end{gathered}
$$

where $N_{s}$ is the total number of intervals (months) out of $N$ (months) that the demand was met.

Resilience: Resilience is a measure of the reservoir's ability to recover from failure and the most widely used definition of resilience is due to Hashimoto et al. (1982):

$$
\varphi=1 /\left(f_{d} / f_{s}\right)=f_{s} / f_{d} ; \quad 0<\varphi \leq 1
$$

where $\varphi$ is resilience, $f_{s}$ is number of continuous sequences of failure periods and $f_{d}$ is the total duration of the failures, i.e., $f_{d}=N-N_{s}$.

Vulnerability: The definition of vulnerability used here is due to Sandoval-Soils et al. (2011) and is the average period shortfall as a ratio of the average period demand, i.e.,:

$$
\eta=\sum_{t=1}^{f_{d}}\left[\left(D_{t}-D_{t}^{\prime}\right) / D_{t}\right] / f_{d} ; t \in f_{d}
$$

where $\eta$ is vulnerability (dimensionless) and all other terms are as defined previously. 
Sustainability: A sustainability index that integrates the three earlier defined indices was used (Sandoval-Soils et al. 2011):

$$
\lambda_{1}=\left(R_{t} \varphi(1-\eta)\right)^{1 / 3}
$$

where $\lambda_{1}$ is the sustainability. Because $R_{v}$, unlike $R_{t}$, is less likely to be dramatically affected by water scarcity, an alternative definition of sustainability index $\left(\lambda_{2}\right) \operatorname{using} R_{v}$ instead of $R_{t}$ was also explored, i.e.,:

$$
\lambda_{2}=\left(R_{v} \varphi(1-\eta)\right)^{1 / 3}
$$

\subsection{HYSIM Rainfall-Runoff Modelling}

HYSIM is a time-continuous, conceptual rainfall-runoff model. The HYSIM model has two sub-routines simulating respectively river basin hydrology and the channel hydraulics to drive the model. The hydrology is simulated with help of seven stores representative of land use and soil type while the hydraulic sub-routine is conducted using kinematic routing of flows. The full structure of the model is schematically illustrated in Fig. 4.

The seven natural stores into which the hydrology routine has been conceptualised comprise interception storage, upper soil horizon, lower soil horizon, transitional groundwater store, groundwater store, snow storage and minor channel storage, all with associated hydrological parameters as detailed by Pilling and Jones (1999). Initial values of some of the panoply of model parameters (see Pilling and Jones 1999) are usually estimated from land use and soil type of the region while others are often extracted from the literature.

Fig. 4 HYSIM schematic

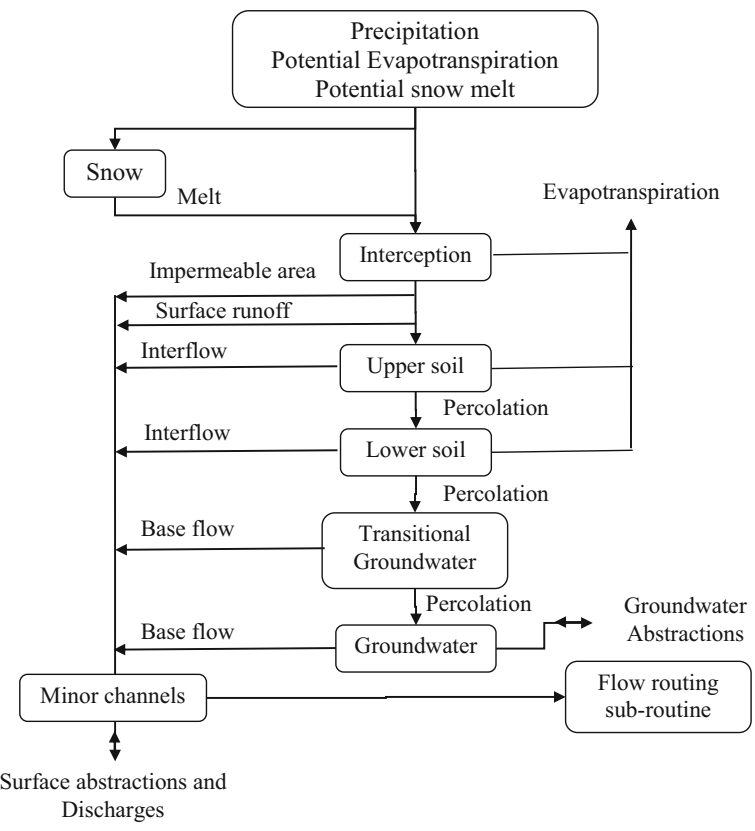


Some of these parameters are later refined by calibration including: rooting depth $(\mathrm{mm})$ [RD], permeability — horizon boundary $(\mathrm{mm} / \mathrm{h})$ [PHB], permeability — base lower horizon, $\mathrm{mm} / \mathrm{h}[\mathrm{PBLH}]$, interflow-upper $(\mathrm{mm} / \mathrm{h})[\mathrm{IU}]$, interflow-lower $(\mathrm{mm} / \mathrm{h})[\mathrm{IL}]$, snow Threshold $[\mathrm{ST}]$, and snow melt rate $[\mathrm{SM}]\left(\mathrm{mm} /{ }^{\circ} \mathrm{C}\right)$. The $\mathrm{RD}$ depends on the type of vegetation but usually ranges between 800 and $5000 \mathrm{~mm}$, with lower value associated with grassland and higher value for woodland. For other parameters like PHB, PBLH, IU and IL, a universal default initial value of $10 \mathrm{~mm} / \mathrm{h}$ is assumed in the model. The snow melt related parameters, i.e., ST and SM, control respectively the temperature below which the precipitation falls as snow and the melt rate in $\mathrm{mm}$ for each degree of temperature above the threshold.

The hydraulics routine routes the flow down the channel using a simple kinematic wave approach, also with associated parameters (Manley and WRA 2006). As will be shown later, the Beas at the Pong catchment was modelled as three sub-catchments in series to account for the spatial variability in the catchment. The relevant channel hydraulics parameters for the three sub-basins in the Beas basin are shown in the Table 1. None of these were optimised during the runs carried out in this study.

HYSIM takes precipitation, temperature and potential evaporation as inputs. The temperature is required for the modelling of snow-melt and accumulation based on the empirical degree-day approach. HYSIM has been extensively used in several research studies including snowy catchments of the United Kingdom to address climate change impacts issues e.g., Pilling and Jones 1999; Arnell 2003.

\section{Case Study \& Data}

The Beas River, on which the Pong dam and its reservoir are located, is one of the five major rivers of the Indus basin, India. The reservoir, located at longitude $76^{\circ} 05 \mathrm{E}$ and latitude $32^{\circ} 01 \mathrm{~N}$, drains a catchment area of $12,561 \mathrm{~km}^{2}$, out of which the permanent snow catchment is $780 \mathrm{~km}^{2}$ (Jain et al. 2007). Active storage capacity of the reservoir is $7290 \mathrm{Mm}^{3}$. The Pong is primarily used for meeting irrigation water demands for which a total of $7913 \mathrm{Mm}^{3}$ is released annually to irrigate $1.6 \mathrm{Mha}$ of land. Hydropower generation is achieved by releasing the water through turbines before it is diverted to the irrigation fields.

The major crops cultivated in the area are rice, wheat and cotton. The seasonal distribution of the irrigation releases is shown in Fig. 5 which reveals rises during the Kharif (June-October) cultivation season to cater for the water-intensive paddy rice cultivation during this season. Less water is released during the Rabi cultivation season (November-April); indeed, as Fig. 5 reveals, the irrigation release is least in April at the

Table 1 HYSIM hydraulic parameters

\begin{tabular}{llll}
\hline Parameters & \multicolumn{2}{l}{ Sub-catchment } & \\
\cline { 2 - 4 } & Upper & Middle & Lower \\
\hline Channel roughness & 0.03 & 0.03 & 0.03 \\
Reach gradient & 0.035 & 0.007 & 0.0025 \\
Flood plain roughness & 0.10 & 0.10 & 0.10 \\
\hline
\end{tabular}


Fig. 5 Average monthly inflows and releases from Pong dam (2000-2008)

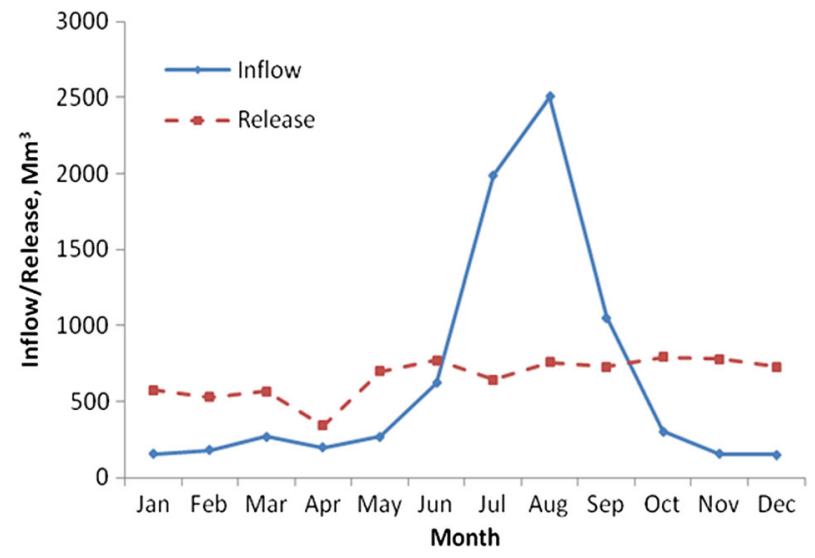

end of the Rabi when only minor vegetables are cultivated. Monsoon rainfall between June and September is a major source of water inflow into the reservoir, apart from snow and glacier melt. Snow and glacier melt runoff in Beas catchment was studied from 1990 to 2004 by Kumar et al. (2007) and its contribution is about $35 \%$ of the annual flow at Pandoh Dam (upstream of Pong dam).

Monthly reservoir inflow and release data from January 2000 to December 2008 (9 years) were available for the study. The historic mean annual runoff (MAR) at dam site is $8485 \mathrm{Mm}^{3}$ (annual coefficient of variation is 0.225 ) and the seasonal distribution of the annual runoff is also shown in Fig. 5 which, when compared with the irrigation releases (shown on the same plot), clearly demonstrates that apart from the brief Monsoon interregnum during JuneAugust/September, the natural river flow in the Beas cannot sustain the irrigation water demands without a reservoir. The discrepancy between the river flow and irrigation demand accentuates during the post-Monsoon (September-November) period which also coincides with the major Rabi growing season in the region.

Gridded TRMM (TRRM 3B42 V7) daily rainfall data that span the runoff period were used for the study. The TRMM data have a fine spatial resolution $\left(0.25^{\circ} * 0.25^{\circ}\right)$, covering the latitudinal band of $50^{\circ} \mathrm{N}-\mathrm{S}$. Since potential evapotranspiration $\left(\mathrm{ET}_{\mathrm{o}}\right)$ measurements were unavailable, estimates were obtained using the Penman-Monteith (P-M) formulation forced with meteorological variables from the NCEP Climate Forecast System Reanalysis (CFSR) data from January 1999-December 2008.

As a way of accommodating the spatial variability within the catchment, the Beas catchment was divided into three sub-basins as shown in Fig. 1, based on consideration of altitude, spatial difference and available meteorological data. The upper, middle and lower sub-catchment areas are respectively 5720,3440 and $3350 \mathrm{~km}^{2}$. Because the horizontal resolution available for precipitation and temperature were different, the number of grids used to average precipitation, snowmelt and evapotranspiration were also different. As explained earlier in Section 2.4, HYSIM hydrological parameters were initialised with the help of the Harmonized World Soil Database (HWSD) analysis: the area of each soil type of the catchment was taken into account to get an average value of hydrological parameters. These parameters were then modified during the calibration of the model.

The summary of the rainfall, temperature and the estimated $\mathrm{P}-\mathrm{MET}_{\mathrm{O}}$ data for the three subcatchments are shown in Table 2. 


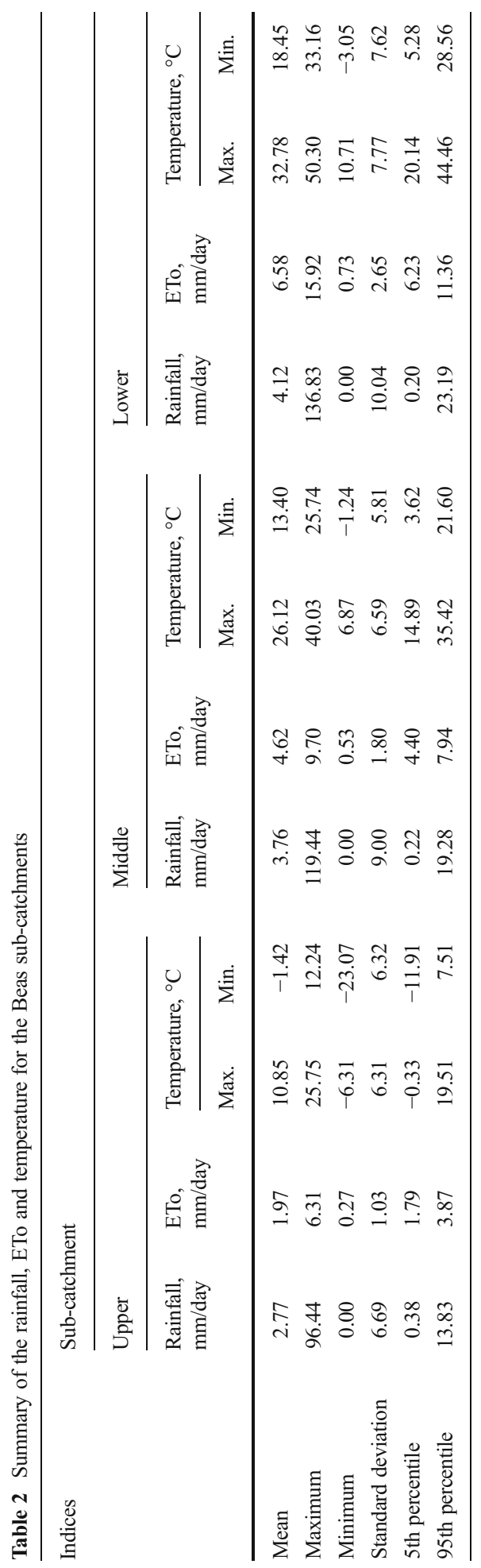




\section{Results and Discussion}

\subsection{Hysim Calibration}

The available flow record (1998-2008) was split into three: 1998-1999 (2 years) period was used for model warm-up, January 2000-December 2004 period was used for model calibration and January 2005-December 2008 period was used for model validation.

The performance of the model during calibration and validation is shown in Fig. 6a and b respectively. These relate to the entire catchment and show that the model has performed reasonably well in reproducing the measured runoff, with $\mathrm{R}^{2}$ of 0.92 and 0.83 during calibration and validation, respectively. The estimated Nash-Sutcliffe efficiency indices during the calibration and validation were respectively 0.88 and 0.78 , both of which lend further credence to the modelling skill of the calibrated HYSIM. Although the magnitudes of the high flows were not well simulated, their timing was perfectly synchronised with the observed. More re-assuring, however, is the relatively better performance of the model in simulating the low runoff sequence in the data, which is more important for water resources planning than the high flows periods.

\subsection{Rule Curves and Hedging Policy}

The optimized rule curves obtained via GA are shown in Fig. 7, together with the approximate rule curves developed using the SPA. In general, the interval $\left[\mathrm{URC}_{\mathrm{m}}, \mathrm{LRC}_{\mathrm{m}}\right]$ for $\mathrm{GA}$ optimized curves is everywhere wider than that of the SPA, implying that more water will be available for supply using the former, with implications for the overall performance of the
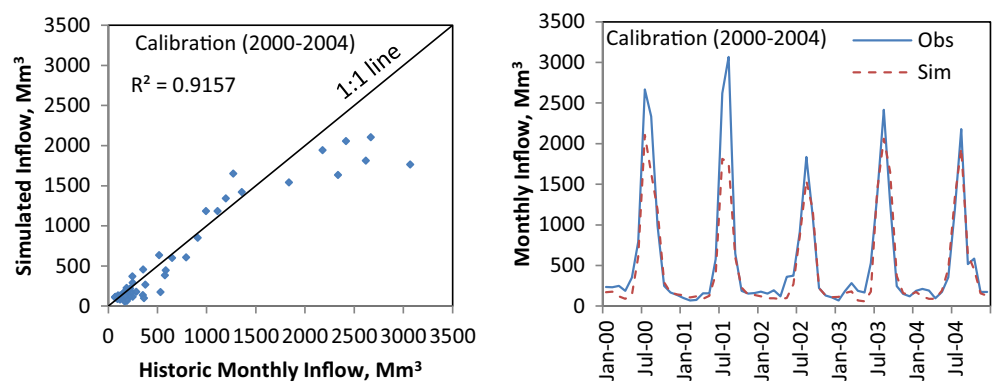

(a)
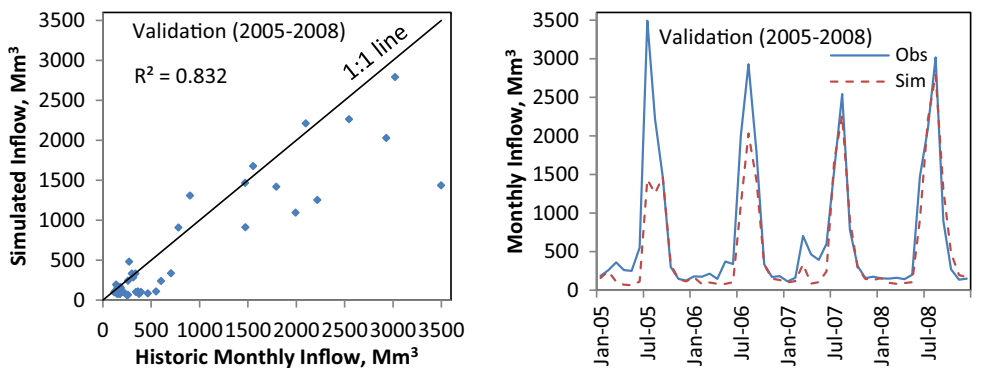

(b)

Fig. 6 Comparison of observed and simulated monthly river flow during: a calibration; and $\mathbf{b}$ validation 


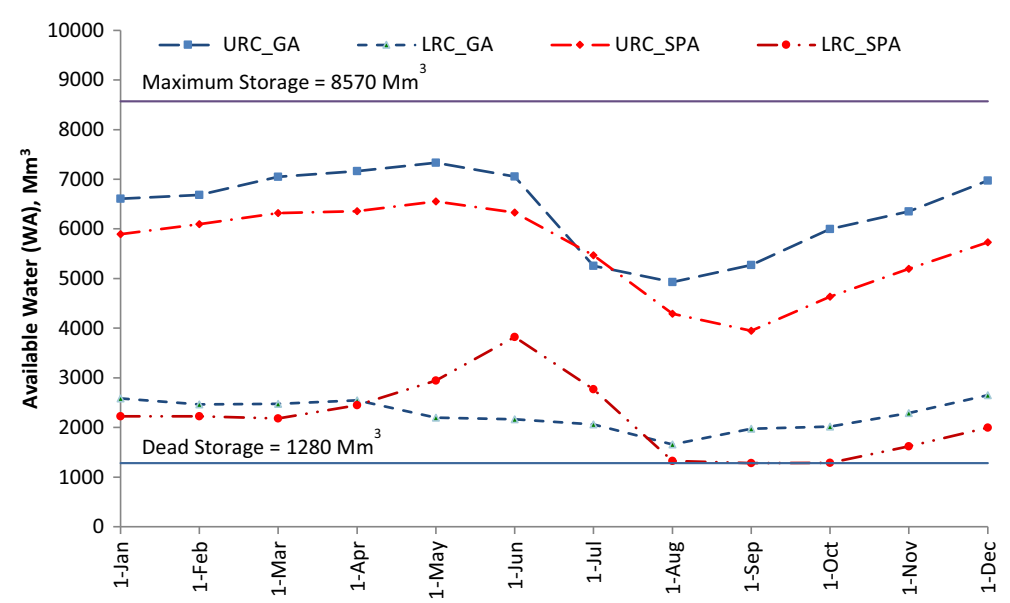

Fig. 7 Rule curves developed by coupled SPA-GA optimisation

reservoir. The GA optimized URC is compatible with the inflow pattern (se Fig. 5) at the Pong because when the inflow is increasing rapidly from June to August in response to the Monsoon, the rule curve ordinates are falling to accommodate the increasing inflows within the reservoir. The maximum ordinate of the URC occurs around May just before the onset of the Monsoon and falls throughout June-August to accommodate the large runoff generated by the Monsoon. In this way, the rule curves will be helping to protect against any flooding potential in the basin during the Monsoon season.

The GA-optimised rule curves with the hedging curve superimposed are shown in Fig. 8. The CRC effectively partitions the previous zone of normal operation $\left[\mathrm{LRC}_{\mathrm{m}}, \mathrm{URC}_{\mathrm{m}}\right]$ into two: an upper part in which meeting the full demand will be attempted and a lower part in which the supply will be curtailed to 0.827 of the full demand. As seen in Fig. 8, while reductions are recommended throughout the annual supply cycle, the situation is much more prevalent in the winter months where very few occasions of full supply can be seen. The Monsoon season, June-September is a period of high reservoir inflows and as seen in Fig. 8, there is a generous scope for meeting the full demand during this period and the period immediately preceding the Monsoon, the latter in anticipation of the high inflow expected

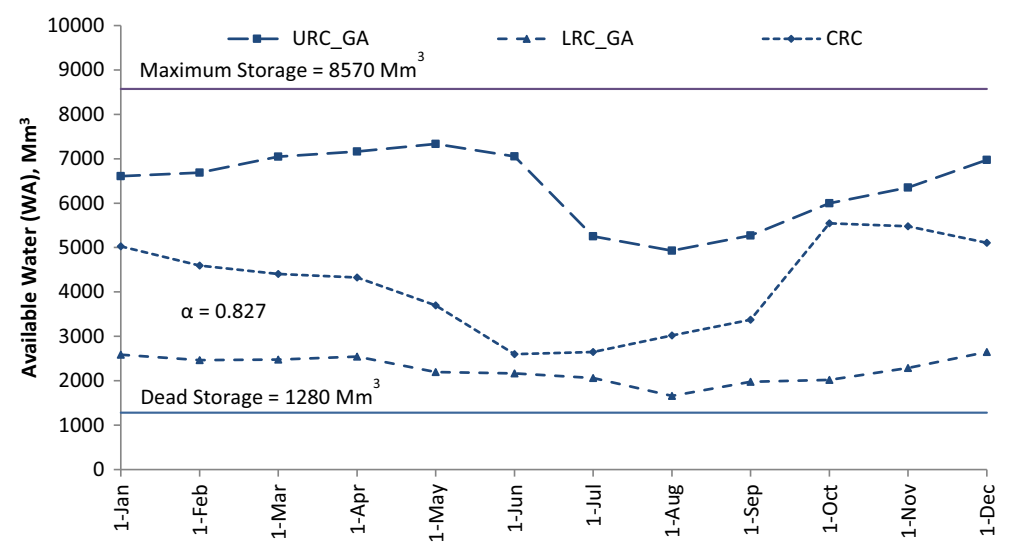

Fig. 8 GA optimised hedging- integrated rule curves for the Pong Reservoir 
during the Monsoon. As the post-Monsoon season approaches, however, the possibility of meeting the full demand diminishes and near-universal rationing or hedging occurs. Although the effect of the rationing on the performance of the reservoir will be discussed later, the rationing ratio of 0.827 , i.e., a reduction of a mere $17 \%$ in the amount demanded, is quite modest and not expected to cause too much disruption in terms of the total volume of water supplied, i.e., the volumetric reliability.

\subsection{Simulated Performance for the Pong Reservoir Under Current Conditions}

The results of the performance simulations for the different rule curves are summarised in Table 3 for the simulated historic runoff scenario. For convenience, the basic, no-hedging policy is denoted by $\mathrm{H} 0$, while the hedging-integrated policy has been denoted by H1. A quick comparison of $R_{t}$ and $R_{v}$ values will reveal that $R_{v}>R_{t}$ for both $H 0$ and $H 1$, as expected. In terms of the total amount of water released over the 108 months of the simulation, $\mathrm{H} 0$ was marginally better than $\mathrm{H} 1\left(\mathrm{R}_{\mathrm{v}}\right.$ of $93.6 \%$ for $\mathrm{H} 0$ versus $90.0 \%$ for $\left.\mathrm{H} 1\right)$; however, this has masked the fact that with $\mathrm{H} 0$, the reservoir suffered large single period shortages (maximum= $607 \mathrm{Mm}^{3}$ or $23.4 \%$ of the corresponding month demand), whereas the corresponding value was $392 \mathrm{Mm}^{3}$ (or $7.4 \%$ of the demand) for H1. Such single period large shortages are unacceptable for a water supply system because of its effect on water users. The vulnerability $(\eta)$ for H0 $(=0.61)$ is almost three times as high as that for $\mathrm{H} 1(=0.20)$. This situation highlights the benefit of water saving during normal reservoir operation because, as clearly demonstrated in this study, it can bring about a significant reduction in the impacts (or vulnerability) of water shortage.

The reductions in the number and amount of large single-period shortages often come at the expense of larger number of periods of moderate and small water shortages and this is no exception in the current study. For example as seen in Table 3, while the number of occasions in which demand was unmet $\left(\mathrm{f}_{\mathrm{d}}\right)$ was only 13 for $\mathrm{H} 0$, this has grown to 58 months for $\mathrm{H} 1$. This has in turn affected the systems $R_{t}$, which deteriorated from about $88 \%$ for $\mathrm{H} 0$ to $46 \%$ for $\mathrm{H} 1$. However, as noted by Adeloye (2012), this should not be a source of concern since in terms of water availability as characterised by the $R_{v}$ the systems performance is still largely acceptable.

The resilience of the reservoir, $\varphi$, is better for $\mathrm{H} 0$ when compared to $\mathrm{H} 1$. Although both $\mathrm{H} 0$ and $\mathrm{H} 1$ recorded comparable number of independent failure sequences $\left(\mathrm{f}_{\mathrm{s}}\right)$, the resilience with $\mathrm{H} 1$ was worse than that with $\mathrm{H} 0$ because of the longer number of failure durations for the former $\left(f_{d}=58\right.$ months compared to $f_{d}=13$ months for $\left.H 0\right)$. The sustainability, $\lambda$, is shown in the last two columns of Table 3. On the basis of this sustainability, $\mathrm{H} 0$ would be regarded as a better policy than $\mathrm{H} 1$, if the $R_{t}$ was used in computing the $\lambda_{1}$ (see Eq. (15)). However, when the $R_{v}$ was used in calculating the sustainability (see Eq. (16)), the $\lambda_{2}$ was indistinguishable between $\mathrm{H} 0$ and $\mathrm{H} 1$ (0.52 as against the 0.5 for $\mathrm{H} 1)$.

\subsection{Climate Change Effects on Runoff and Reservoir Performance}

\subsubsection{Effects on Runoff}

Delta perturbations in annual rainfall considered were -10 to $+10 \%$ with an increment of $5 \%$; corresponding temperature changes were 0 to $2{ }^{\circ} \mathrm{C}$, step of unity. The mean values of the simulated annual and seasonal runoff are shown in Fig. 9. In general, reducing the rainfall causes the resulting runoff to reduce irrespective of the temperature situation. However, the simulation has also revealed a large influence of the melting glacier and seasonal snow on the 


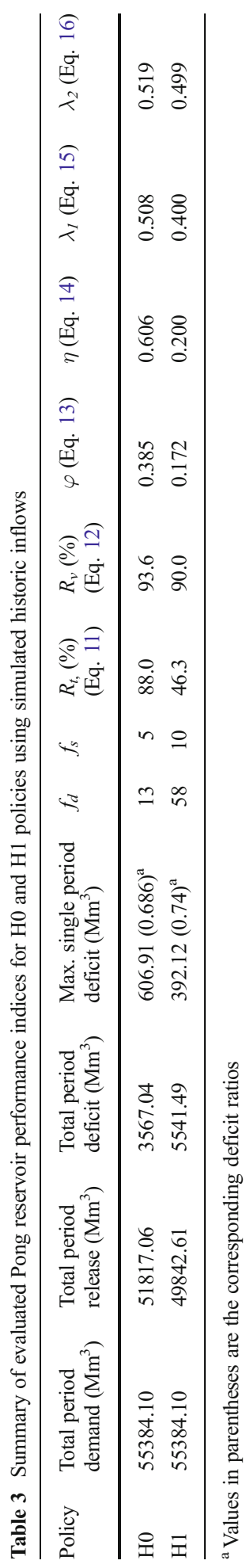



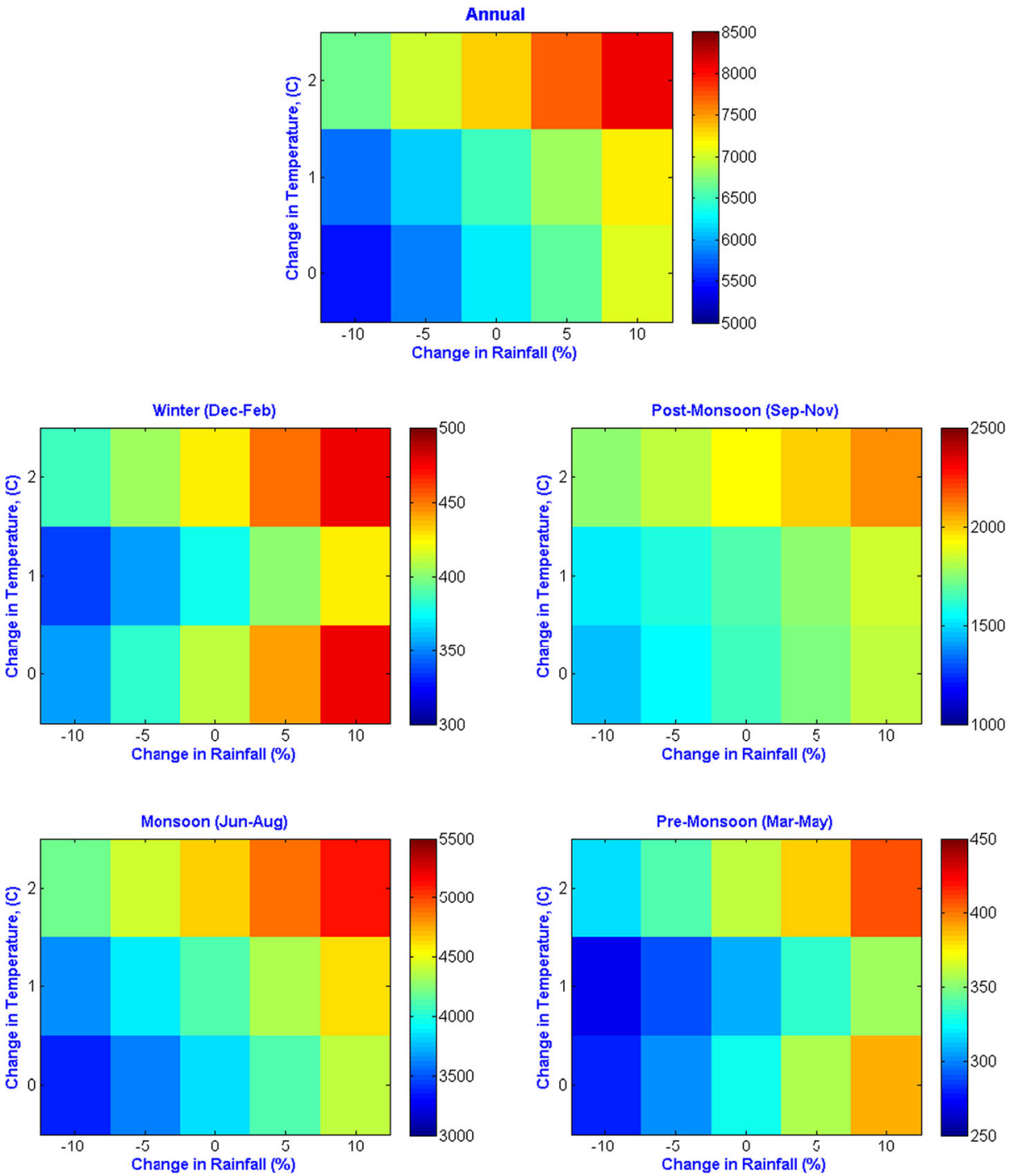

Fig. 9 Simulated mean annual and seasonal runoff at the Pong $\left(\mathrm{Mm}^{3}\right)$

runoff, where on an annual scale, changing the temperature by $2{ }^{\circ} \mathrm{C}$ is causing the runoff to increase by about a third. The simulations also reveal the dominance of the Monsoon effect on the runoff of the Pong. For example, of the simulated maximum mean annual runoff of about $8200 \mathrm{Mm}^{3}$, almost $88 \%$ of this $\left(7300 \mathrm{Mm}^{3}\right)$ was contributed during the Monsoon and postmonsoon periods, with both the winter (December-February) and pre-monsoon (March-May) periods contributing the remaining $12 \%$. This further reinforces the importance of the Monsoon in ensuring the water security of the Beas and indeed the whole of India.

Table 4 summarises the percentage change in annual and seasonal runoff from simulated historic. As expected, increasing the rainfall causes the annual runoff to increase and vice versa, for temperature change from 0 to $2{ }^{\circ} \mathrm{C}$. However, while increasing or decreasing the rainfall by the same amount has resulted in similar absolute change in the runoff for no change 
Table 4 Change (\%) in mean annual and seasonal runoff under climate change

\begin{tabular}{lrrrrr}
\hline Temperature change, ${ }^{\circ} \mathrm{C}$ & \multicolumn{3}{l}{ Annual rainfall change, $\%$} & & \\
\cline { 2 - 6 } & -10 & -5 & 0 & +5 & +10 \\
\hline Annual & & & & & \\
0 & -12.11 & -6.25 & 0.00 & 6.70 & 13.77 \\
1 & -7.08 & -1.63 & 4.17 & 10.21 & 16.44 \\
2 & 6.98 & 12.41 & 18.19 & 24.27 & 30.51 \\
Season: winter (December-February) & & & & \\
0 & -13.25 & -6.82 & 0.00 & 7.77 & 16.40 \\
1 & -18.32 & -13.55 & -8.19 & -2.36 & 3.81 \\
2 & -5.90 & -1.23 & 4.00 & 9.75 & 15.83 \\
Season: post-monsoon (September to November) & & & & \\
0 & -10.80 & -5.54 & 0.00 & 5.83 & 11.93 \\
1 & -7.60 & -2.80 & 2.30 & 7.54 & 12.81 \\
2 & 6.88 & 11.63 & 16.71 & 21.99 & 27.29 \\
Season: monsoon (June to August) & -12.29 & -6.35 & 0.00 & 6.76 & 13.85 \\
0 & -4.74 & 1.03 & 7.13 & 13.48 & 20.03 \\
1 & 9.25 & 15.01 & 21.07 & 27.42 & 33.96 \\
2 & & & & & \\
Season: pre-monsoon (March-May) & -15.09 & -7.92 & 0.00 & 8.89 & 18.82 \\
0 & -17.76 & -12.05 & -5.72 & 1.09 & 8.29 \\
1 & -2.96 & 3.03 & 9.70 & 16.94 & 24.58 \\
2 & & & &
\end{tabular}

in temperature, the situation is quite different when temperature increases also considered. For example, as shown in Table 4, an increase in annual rainfall of $5 \%$ produced a $10.21 \%$ increase in the annual runoff if the temperature increased by $1{ }^{\circ} \mathrm{C}$; however, a similar decrease in rainfall with the $1{ }^{\circ} \mathrm{C}$ temperature increase only resulted in a decrease of only $1.6 \%$ in the annual runoff. As noted previously, the Beas hydrology is heavily influenced by the melting snow from the Himalayas and what these results show is that runoff contributed by the melting snow partially compensates for the reduction in direct runoff caused by the combined effects of lower rainfall and higher (temperature-induced) evapotranspiration. Indeed, as the assumed temperature increase becomes higher, the effect of any reduction in the annual rainfall fully disappears, resulting in a net increase in the annual runoff. Consequently, increasing the temperature by $2{ }^{\circ} \mathrm{C}$ has resulted in a net increase in the annual runoff of 12.4 and $7 \%$ for 5 and $10 \%$ reductions respectively in the annual rainfall.

The annual runoff situation presented above masks the significant seasonal differences in the simulated runoff response of the Beas. As Table 4 clearly shows, both the post-Monsoon and winter seasons that do not benefit from the melting snow and its associated runoff tended to be well-behaved in terms of the response, with reductions in the rainfall producing significant reductions in the generated runoff. Indeed, for these two seasons, increasing the temperature can worsen the runoff situation even for situations in which the rainfall has increased, as clearly revealed by the $2.4 \%$ reduction in the winter runoff with $1{ }^{\circ} \mathrm{C}$ and $5 \%$ rises, respectively in the temperature and rainfall. These situations must be resulting from the 
dominance of the evapotranspiration loss, which in the absence of additional water from melting snow will make the runoff to decrease.

\subsubsection{Effects on Reservoir Performance}

The complete array of the evaluated performance measures when the reservoir was operated with the historic basic rule curves (H0) and hedging integrated rule curves (H1) for the investigated climate change conditions is shown in Table 5. All the performance indices examined for the current conditions (see Table 3) were also evaluated for the climate change conditions but given the direct relevance of the vulnerability to the water shortage/stress situation, the following discussion will focus on the vulnerability.

As Table 5 shows, as the rainfall decreases, the vulnerability of the system is heightened (e.g., from 0.61 to 0.66 for a $10 \%$ fall in rainfall and no temperature change) with $\mathrm{H} 0$. The corresponding change with $\mathrm{H} 1$ is from 0.20 to 0.26 which unlike the 0.66 with $\mathrm{H} 0$ would still be deemed acceptable for any major water resources system (see Fiering 1982). The implication of this is that, although the Pong has benefitted by being in a catchment that receives snow, the current study has ramifications much wider than the Beas and its Pong reservoir because the hedging still produced significant improvement in vulnerability without such additional runoff from melting snow. This is a significant outcome because, although the effectiveness of hedging in tempering vulnerability has been widely acknowledged, the fact that hedging can also be used for reducing the impact of water shortages associated with climate change is a new thing as far as the authors are aware.

As the catchment becomes wetter, occurrences of water shortage reduce with $\mathrm{H} 1$ and as Table 5 shows, increasing the rainfall by $10 \%$ has reduced the vulnerability to $18 \%$ if the temperature remains unchanged.

The effect of changes in temperature on the runoff was carried through to the estimated performances for the Pong as shown in Table 5. Thus, in the case of the vulnerability, increasing the temperature for no increase in rainfall caused the vulnerability to reduce for both $\mathrm{H} 0$ and $\mathrm{H} 1$. Thus, a $2{ }^{\circ} \mathrm{C}$ rise in temperature caused the vulnerability to change from 0.61 to 0.47 for $\mathrm{H} 0$ while the corresponding values are 0.2 to 0.18 for $\mathrm{H} 1$. The influence of additional rainfall on this vulnerability situation was, however, not so significant. For example, combining $10 \%$ increase in the rainfall and $2{ }^{\circ} \mathrm{C}$ increase in temperature has only resulted in a marginal change in the vulnerability, i.e., 0.17 versus 0.18 for $\mathrm{H} 1$ and 0.472 versus 0.474 for H0. This may be explained by the fact that the rainfall increase is likely to be during the Monsoon period when the reservoir is likely to be full and hence any additional water is likely to be spilled over the spillway. This additional water may therefore not be contributing much in reducing the vulnerability during the dry periods. In any case as noted previously with the rule curves, the tendency is to always meet the full demand during the Monsoon period with very limited hedging prescribed by the critical rule curve during this period.

The above results would imply that the Pong is not performing satisfactorily in meeting the demand because of the high vulnerability or average maximum single period water shortage of over $61 \%$. The simulation results have also shown that without a system of hedging, the vulnerability will worsen to almost $66 \%$ if the rainfall decreases by $10 \%$. Increasing the rainfall by $10 \%$ produces the opposite effect on the runoff but the resulting vulnerability is still almost $50 \%$. Both of these situations are tempered if the temperature also increases because of the additional runoff generated by the melting glacier and seasonal snow; however, even with this, the vulnerability will still be as high as $47 \%$ for H0. As noted by Fiering (1982), most 


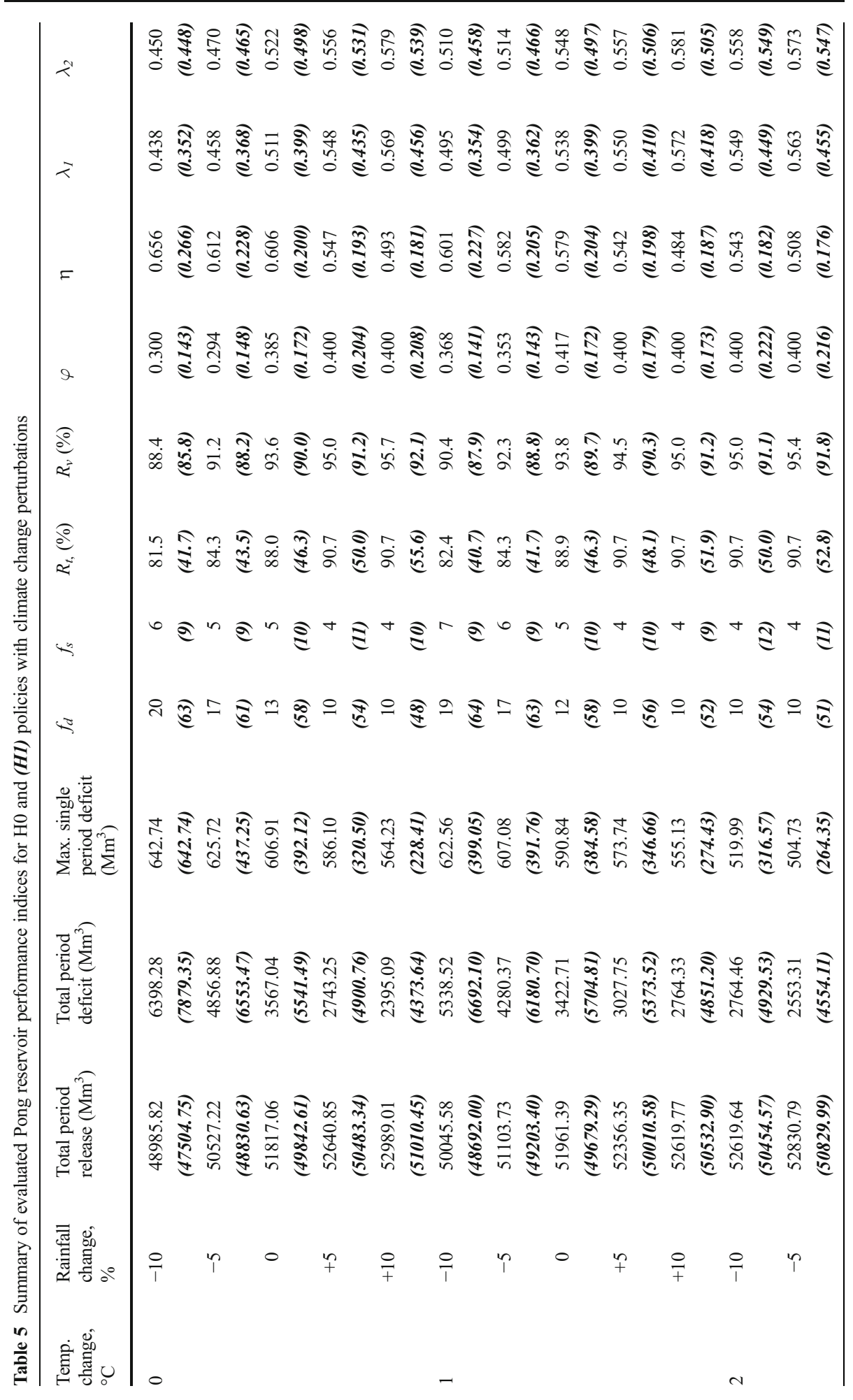




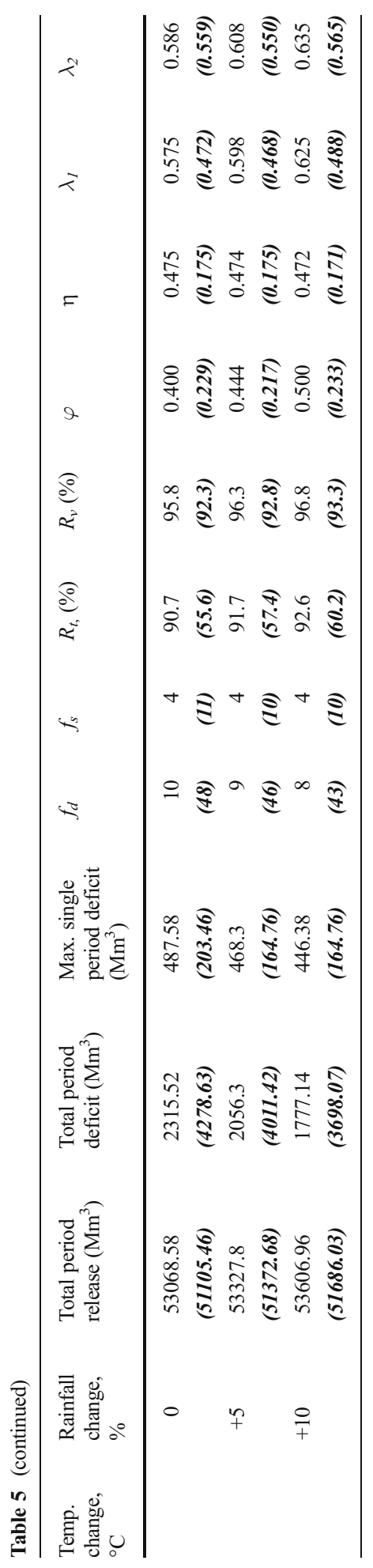


water users are able to cope with water shortage of up to $25 \%$ of that required but significant consequences can result at shortages above this critical threshold. The hedging-integrated rule curves $\mathrm{H} 1$ developed in this work has shown that significant reduction in the vulnerability is possible with moderate hedging.

Figure 10a-c compare $\mathrm{H} 0$ and $\mathrm{H} 1$ in terms of three of the performance indices for the Pong: $\mathrm{R}_{\mathrm{t}}, \mathrm{R}_{\mathrm{v}}$ and $\eta$. As expected, $\mathrm{R}_{\mathrm{t}}$ (see Fig. 10a) is significantly affected by hedging in H1 which has caused it to significantly decrease (relative to the $\mathrm{H} 0$ situation) because of the increased number of failures arising from the deliberate withholding of almost $17 \%$ of the full demand even where there is sufficient water to meet the demand. On the contrary, $\mathrm{R}_{\mathrm{v}}$ for $\mathrm{H} 1$ is almost indistinguishable from its $\mathrm{H} 0$ counterpart and is further proof that hedging does not necessarily cause any significant deterioration in the overall quantity of water supplied (see Fig. 10b).

The main influence of hedging is on the vulnerability which, as the two plots in the Fig. 10c have shown, has significantly benefitted through hedging. The target vulnerability of 0.25 suggested by Fiering (1982) has been drawn as the horizontal line in Fig. 10c from where it is clear that the vulnerability will always be higher than 0.25 for $\mathrm{H} 0$, both for existing (i.e.,

(a) Time reliability $\left(\mathrm{R}_{\mathrm{t}}\right)$
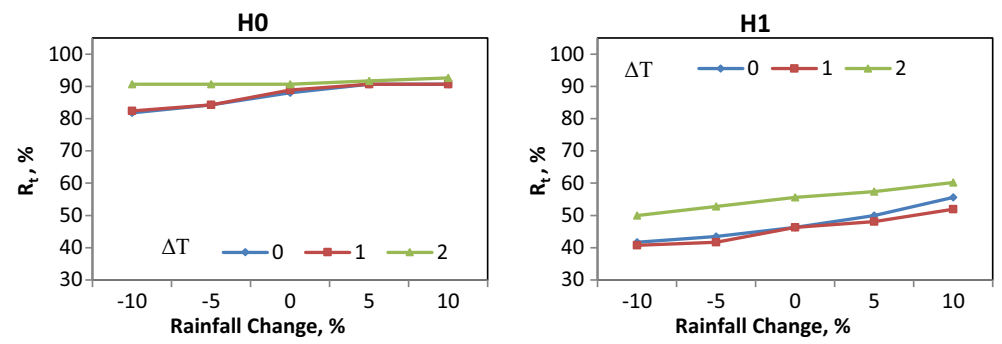

(b) Volumetric reliability $\left(\mathrm{R}_{\mathrm{v}}\right)$
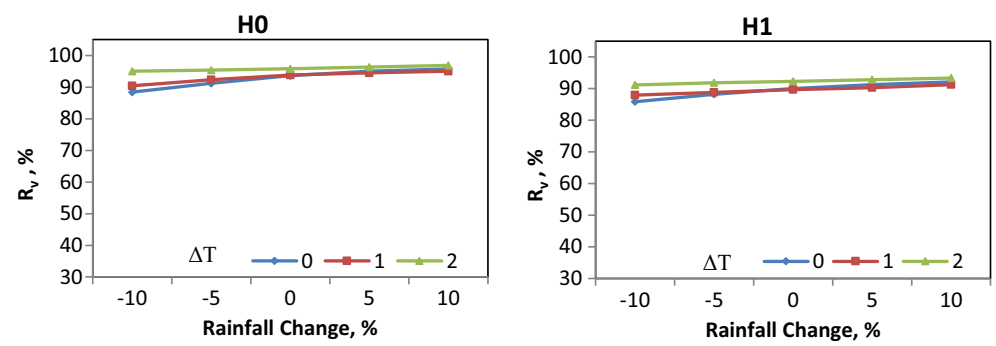

(c) Vulnerability $(\eta)$
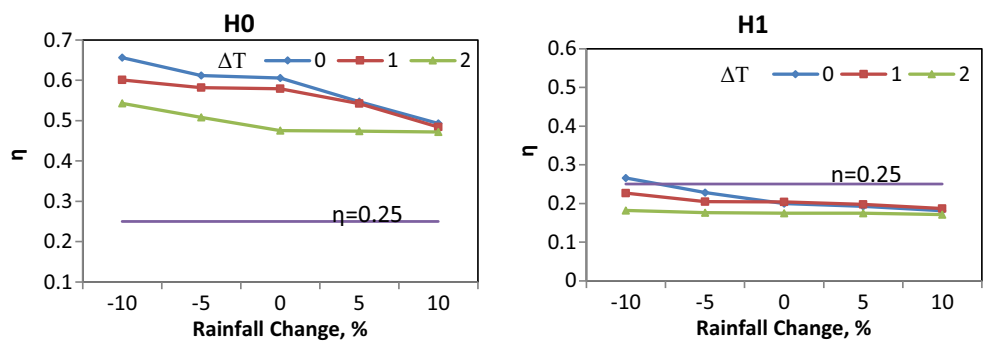

Fig. 10 Pong reservoir simulated performance indices compared for $\mathrm{H} 0$ and $\mathrm{H} 1$ operating policies 
historic) and the climate change situations. The situation is, however, completely different with H1 where, except when the rainfall decreases by $10 \%$, the vulnerability is always below $25 \%$. Several studies have demonstrated that hedging can reduce the vulnerability by ensuring that shortages are spread evenly instead of a mixture of large and crippling shortages that can result if there was no hedging and the results obtained in this study have confirmed that.

\section{Conclusions}

This study has assessed the impact of plausible changes in the climate on both the inflows and performance of the Pong reservoir in India. The impact simulations with HYSIM showed that increasing the rainfall will cause the runoff (and hence reservoir inflow) to increase while decreasing it will result in the opposite effect. However, if the changes in rainfall are accompanied by increases in the temperature, the effect of decreases in rainfall on the runoff is somewhat tempered due to that additional runoff generated by melting snow with the rise in temperature. This shows the buffering effect of the snow on this catchment which may be lost if projected climate change results in the depletion of the snow cap in the Himalayas where the catchment is situated.

As far as reservoir performance is concerned, the most significant effect of the hedging policy was on the reservoir vulnerability which reduced from 61 to $20 \%$ when hedging was implemented. Even with climate change causing significant reductions in reservoir inflow, hedging was still able to improve the vulnerability from $66 \%$ to a mere $26 \%$. These are moderate water shortages that most water users can tolerate and have been brought about by a modest cut back of $17 \%$ in the amount of water supplied during normal operational periods.

This study has thus demonstrated the effectiveness of improved operational practices in mitigating climate change impacts on water resources infrastructures that removes the need for new builds or physical capacity expansion. In particular for the Pong reservoir, incorporating a hedging policy with operational rule curves can help reduce the system vulnerability significantly without any adverse effect on the total volume of water supplied. No doubt, the Pong reservoir has benefitted by being in a catchment that receives snow but even when this factor is not taken into consideration, the effect of water hedging is still very considerable, with implications for catchments without snow/glaciers. With regard to the contributions of the snow and glacier, their predicted gradual disappearance due to climate change could be significant and deserves further investigation.

Acknowledgements The work reported here was funded by the UK-NERC (Project NE/1022337/1) - Mitigating Climate Change impacts on India Agriculture through Improved Irrigation Water Management (MICCI) - as part of the UK-India Changing Water Cycle (CWC South Asia) thematic Programme.

Open Access This article is distributed under the terms of the Creative Commons Attribution 4.0 International License (http://creativecommons.org/licenses/by/4.0/), which permits unrestricted use, distribution, and reproduction in any medium, provided you give appropriate credit to the original author(s) and the source, provide a link to the Creative Commons license, and indicate if changes were made.

\section{References}

Adeloye AJ (2012) Hydrological sizing of water supply reservoir. In: Bengtsson L, Herschy RW, Fairbridge RW (eds) Encyclopedia of lakes and reservoirs. Springer, Dordrecht, pp 346-355

Adeloye AJ, Montaseri M, Garmann C (2001) Curing the misbehavior of reservoir capacity statistics by controlling shortfall during failures using the modified Sequent Peak Algorithm. Water Resour Res 37(1):73-82 
Adeloye AJ, Nawaz NR, Bellerby TJ (2013) Modelling the impact of climate change on water systems and implications for decision makers. Chapter 11. In: Surampali RY et al (eds) Climate change modelling, mitigation, and adaptation. Environmental \& Water Resources Institute, ASCE, 299-326

Arnell NW (2003) Relative effects of multi-decadal climatic variability and changes in the mean and variability of climate due to global warming: future stream flows in Britain. J Hydrol 270:195-213

Burn HD, Simonovic SP (1996) Sensitivity of reservoir operation performance to climatic change. Water Resour Manag 10(6):463-478

Chiamsathit C, Adeloye AJ, Soundharajan B (2014) Assessing competing policies at Ubonratana reservoir, Thailand. Proc ICE-Water Manag 167(10):551-560

Dariane AB, Karami F (2014) Deriving hedging rules of multi-reservoir system by online evolving neural networks. Water Resour Manag 28:3651-3665

Draper AJ, Lund JR (2004) Optimal hedging and carryover storage value. J Water Resour Plan Manag 130(1): 83-87

Eum H, Kim Y, Palmer R (2011) Optimal drought management using sampling stochastic dynamic programming with a hedging rule. J Water Resour Plan Manag 137(1):113-122

Fiering MB (1982) Estimates of resilience indices by simulation. Water Resour Res 18(1):41-50

Fowler HJ, Kilsby CG, O'Connell PE (2003) Modeling the impacts of climatic change and variability on the reliability, resilience and vulnerability of a water resource system. Water Resour Res 39(8):1222

Fowler HJ, Blenkinsop S, Tebaldi C (2007) Linking climate change modelling to impacts studies: recent advances in downscaling techniques for hydrological modelling. Int J Climatol 27(12):1547-1578

Hashimoto T, Stedinger JR, Loucks DP (1982) Reliability, resilience and vulnerability criteria for water resources system performance evaluation. Water Resour Res 18(1):14-20

Hossain MS, El-shafie A (2013) Intelligent systems in optimizing reservoir operation policy: a review. Water Resour Manag 27:3387-3407

IPCC (2007) Summary for policymakers. Climate Change 2007: the physical science basis, Contribution of the Working Group I to the Fourth Assessment Report of the Intergovernmental Panel on Climate Change, Cambridge University Press

Jain SK, Agarwal PK, Singh VP (2007) Hydrology and water resources of India. Springer, The Netherlands

Kumar V, Singh P, Singh V (2007) Snow and glacier melt contribution in the Beas River at Pandoh Dam, Himachal Pradesh, India. Hydrol Sci J 52(2):376-388

Li L, Xu H, Chen X (2009) Streamflow forecast and reservoir operation performance assessment under climate change. Water Resour Manag 24:83-104

Manley RE, Water Resources Associates (WRA) (2006) A guide to using HYSIM. R.E. Manley and water resources associates Ltd

MATLAB (2004) Genetic algorithm and direct search toolbox - user's guide. Math Works, MA

McMahon TA, Adeloye AJ (2005) Water resources yield. Water Resources Publications, Littleton

McMahon TA, Adeloye AJ, Zhou SL (2006) Understanding performance measures of reservoirs. J Hydrol 324: 359-382

Michalewicz Z (1992) Genetic algorithms + data structures = evolution programs. Springer, New York

Nawaz NR, Adeloye AJ (2006) Monte Carlo assessment of sampling uncertainty of climate change impacts on water resources yield in Yorkshire, England. Clim Chang 78:257-292

Neelakantan TR, Pundarikanthan NV (1999) Hedging rule optimization for water supply reservoirs system. Water Resour Manag 13:409-426

Peng Y, Chu J, Peng A, Zhou H (2015) Optimisation operation model coupled with improving water transfer rules and hedging rules for inter-basin water transfer-supply systems. Water Resour Manag 29:3787-3806

Pilling C, Jones JA (1999) High resolution climate change scenarios: implications for British runoff. Hydrol Process 13(17):2877-2895

Raje D, Mujumdar PP (2010) Reservoir performance under uncertainty in hydrologic impacts of climate change. Adv Water Resour 33:312-326

Rani D, Moreira MM (2010) Simulation-optimisation modelling: a survey and potential application in reservoir systems operation. Water Resour Manag 24:1107-1138

Reddy MJ, Kumar DN (2006) Optimal reservoir operation using multi-objective evolutionary algorithm. Water Resour Manag 20(6):861-878

Sandoval-Soils S, Mckinney DC, Loucks DP (2011) Sustainability index for water resources planning and management. J Water Resour Plan Manag (ASCE) 137(5):381-389

SANDRP (2013) Hydropower generation performance in Beas River basin. South Asia Network on Dams, Rivers and People, New Delhi, India. (http://sandrp.in/HEP_performance_in_Beas_River_ Basin_June2013.pdf)

Shiau JT (2003) Water release policy effects on the shortage characteristics for the Shihmen reservoir system during droughts. Water Resour Manag 17(6):463-480 
Shih JS, ReVelle C (1995) Water supply operations during drought: a discrete hedging rule. Eur J Oper Res 82: 163-175

Taghian M, Rosbjerg D, Haghighi A, Madsen H (2014) Optimization of conventional rule curves coupled with hedging rules for reservoir operation. J Water Resour Plan Manag 140(5):693-698

Tu MY, Hsu NS, Tsai FTC, Yeh WWG (2008) Optimization of hedging rules for reservoir operations. J Water Resour Plan Manag 134(1):3-13

Vicuna S, McPhee J, Garreaud RD (2012) Agriculture vulnerability to climate change in a snowmelt-driven basin in semiarid Chile. J Water Resour Plan Manag ASCE 138(5):431-441

Wardlaw R, Sharif M (1999) Evaluation of genetic algorithms for optimal reservoir operation. J Water Resour Plan Manag (ASCE) 125:25-33

You J-Y, Cai X (2008) Hedging rule for reservoir operations: 2. A numerical model. Water Resour Res 44, W01416 